\title{
BJSM
}

\section{Rehabilitation of shoulder impingement syndrome and rotator cuff injuries: an evidence-based review}

Todd S Ellenbecker and Ann Cools

Br J Sports Med 2010 44: 319-327

doi: $10.1136 /$ bjsm.2009.058875

Updated information and services can be found at:

http://bjsm.bmj.com/content/44/5/319.full.html

These include:

References This article cites 106 articles, 34 of which can be accessed free at: http://bjsm.bmj.com/content/44/5/319.full.html\#ref-list-1

Article cited in:

http://bjsm.bmj.com/content/44/5/319.full.html\#related-urls

Email alerting Receive free email alerts when new articles cite this article. Sign up in the service box at the top right corner of the online article.

Notes

To order reprints of this article go to:

http://bjsm.bmj.com/cgi/reprintform

To subscribe to British Journal of Sports Medicine go to:

http://bjsm.bmj.com/subscriptions 


\title{
Rehabilitation of shoulder impingement syndrome and rotator cuff injuries: an evidence-based review
}

\author{
Todd S Ellenbecker ${ }^{1}$, Ann Cools²
}

1Physiotherapy Associates Scottsdale Sports Clinic,

Scottsdale, Arizona, USA ${ }^{2}$ Department of Rehabilitation Sciences and Physiotherapy, Ghent University, Ghent, Belgium

\section{Correspondence to} Todd S Ellenbecker. Physiotherapy Associates Scottsdale Sports Clinic, 9917 N 95th Street, Scottsdale, AZ 85258,USA; ellenbeckerpt@ cox.net

Accepted 6 January 2010

\begin{abstract}
Rehabilitation of the patient with glenohumeral impingement requires a complete understanding of the structures involved and the underlying mechanism creating the impingement response. A detailed clinical examination and comprehensive treatment programme including specific interventions to address pain, scapular dysfunction and rotator cuff weakness are recommended. The inclusion of objective testing to quantify range of motion and both muscular strength and balance in addition to the manual orthopaedic clinical tests allows clinicians to design evidencebased rehabilitation programmes as well as measure progression and patient improvement.
\end{abstract}

Rehabilitation of the athlete with shoulder impingement is a complex process that requires a comprehensive evaluation and multifactorial treatment programme. The purpose of this article is to present an evidence-based review of the key treatment strategies to rehabilitate and restore shoulder function of the athlete with rotator cuff impingement.

\section{TYPES OF SHOULDER IMPINGEMENT}

Significant advancement in the basic science research in the areas of anatomy and biomechanics of the human shoulder has led to the identification of multiple types of impingement, as well as other causes of rotator cuff pathology, including instability and intrinsic tendon overload. This greater understanding of the cause or causes of impingement can lead to a more specific and non-generalised treatment approach to treat this disorder.

\section{Primary impingement}

Primary compressive disease or impingement is a direct result of compression of the rotator cuff tendons between the humeral head and the overlying anterior third of the acromion, coracoacromial ligament, coracoid or acromial clavicular joint. ${ }^{12}$ The physiological space between the inferior acromion and the superior surface of the rotator cuff tendons has been measured using anteroposterior radiographs and found to be $7-13 \mathrm{~mm}$ in patients with shoulder pain ${ }^{3}$ and $6-14 \mathrm{~mm}$ in normal shoulders. ${ }^{4}$

Neer ${ }^{1} 2$ has outlined three stages of primary impingement as it relates to rotator cuff pathology. These have been extensively reported and referred to in both the surgical and rehabilitative literature, and give the clinician a progressive understanding of the role compressive disease plays in mechanical loading of the rotator cuff.
For the sake of space limitations, additional discussion of these three stages will not be undertaken, however, the reader is referred elsewhere for a complete discussion of these stages. ${ }^{12}$

\section{Secondary impingement}

In addition to impingement playing a primary role, impingement or compressive symptoms may be secondary to underlying instability of the glenohumeral joint. ${ }^{5-7}$ Attenuation of the static stabilisers of the glenohumeral joint, such as the capsular ligaments and labrum, from the excessive demands incurred in throwing or overhead activities can lead to anterior instability of the glenohumeral joint. Due to the increased humeral head translation, the biceps tendon and rotator cuff can become impinged secondary to the ensuing instability. ${ }^{5}$ Also, a progressive loss of glenohumeral joint stability may be created when the dynamic stabilising functions of the rotator cuff are diminished from fatigue, intrinsic overload and subsequent tendon injury. ${ }^{5}$ In addition, rotator cuff impingement can occur secondary to scapular dysfunction. The effects of secondary impingement can lead to rotator cuff tears as the instability and impingement continue. ${ }^{5}$

\section{Internal impingement}

One additional aetiology for rotator impingement in the young athletic shoulder is termed internal, or undersurface, impingement. ${ }^{67}$ This phenomenon was originally identified by Walch et a ${ }^{6}$ during shoulder arthroscopy with the shoulder placed in the $90 / 90$ position. Placement of the shoulder in a position of $90^{\circ}$ of abduction and $90^{\circ}$ of external rotation causes the supraspinatus and infraspinatus tendons to rotate posteriorly. This more posterior orientation of the tendons aligns them such that the undersurface of the tendons rub on the posterior-superior glenoid lip, and become pinched or compressed between the humeral head and the posterosuperior glenoid rim. ${ }^{6}$ Individuals presenting with posterior shoulder pain brought on by positioning of the arm in $90^{\circ}$ of abduction and $90^{\circ}$ or more of external rotation, typically from overhead positions in sport or industrial situations, may be considered as potential candidates for undersurface impingement.

\section{IDENTIFICATION OF UNDERLYING JOINT MOBILITY STATUS}

A systematic approach to shoulder and upper extremity evaluation must be undertaken to identify the specific cause or subtle underlying causes of rotator cuff pathology and/or impingement. Special tests to evaluate the underlying mobility 
status of the glenohumeral joint are key aspects of the evaluation of the patient with rotator cuff pathology. These special tests include the multidirectional instability sulcus sign, ${ }^{8}$ anterior posterior humeral head translation tests or drawer tests, ${ }^{9}$ subluxation relocation test ${ }^{10}$ and Beighton hypermobility index. ${ }^{11}$ These tests can be used to identify glenohumeral joint hypermobility and the presence of subtle underlying instability of the shoulder. These important tests can provide key insights into one of the potential causes of the rotator cuff injury and guide the clinician in the development of an evaluation-based treatment programme. For example, a positive sulcus sign, increased humeral head translation with anterior posterior testing and a positive Beighton hypermobility index would indicate the presence of underlying instability as a contributing factor to a patients' symptoms. A positive subluxation/relocation test indicates both the presence of subtle anterior instability as well as internal undersurface impingement of the rotator cuff. 1012

The use of glenohumeral joint accessory mobilisation, often a mainstay in the treatment of patients with shoulder pathology, would not be indicated in the patient with these positive instability signs. ${ }^{13} 14$ However, for patients who present with glenohumeral joint hypomobility, often seen in patients with primary impingement, the inclusion of select joint mobilisation to restore normal joint arthrokinematics and address capsular tightness or restriction would be indicated. ${ }^{15}$ Failure to identify patients with glenohumeral joint hypermobility and underlying instability properly can result in the inappropriate use of capsular stretching and mobilisation techniques that could further jeopardise shoulder stability and decrease the potential success of the rehabilitation programme, particularly in the overhead athlete.

\section{ROTATIONAL ROM ADAPTATION}

The measurement of glenohumeral joint internal and external rotation range of motion (ROM) is an important part of the evaluation process, and can guide important interventions in the treatment process. The measurement of glenohumeral internal and external rotation should be done with the joint in $90^{\circ}$ of abduction in the coronal plane. ${ }^{16-18}$ Care must be taken to stabilise the scapula with the patient in the supine position, so that the patient's body weight helps to minimise scapular motion. It is recommended that additional stabilisation be provided through the use of a posteriorly directed force by the examiner on the anterior aspect of the coracoid and shoulder during internal rotation ROM measurement (figure 1). This limits scapular compensation and provides a more isolated internal rotation measurement. Bilateral comparison of external and internal rotation ROM should be performed.

One rather consistent finding during the examination of the overhead athlete is increased dominant arm external rotation (defined or referred to as external rotation gain) as well as reduced dominant arm glenohumeral joint internal rotation (glenohumeral internal rotation deficiency, GIRD). ${ }^{18-21}$ Ellenbecker et al have identified that this consistent relationship is only identified in a condition in which glenohumeral joint rotation was measured with the scapula stabilised. ${ }^{22}$ Failure to stabilise the scapula may not reveal the GIRD present as a result of scapular compensation.

Several mechanisms have been proposed to explain this glenohumeral ROM relationship of increased external rotation (external rotation gain) and limited internal rotation (GIRD). ${ }^{19}$ 2324 Tightness of the posterior capsule and stiffness of the muscle tendon unit of the posterior rotator cuff (thixotrophy) have both been described as factors that limit internal glenohumeral

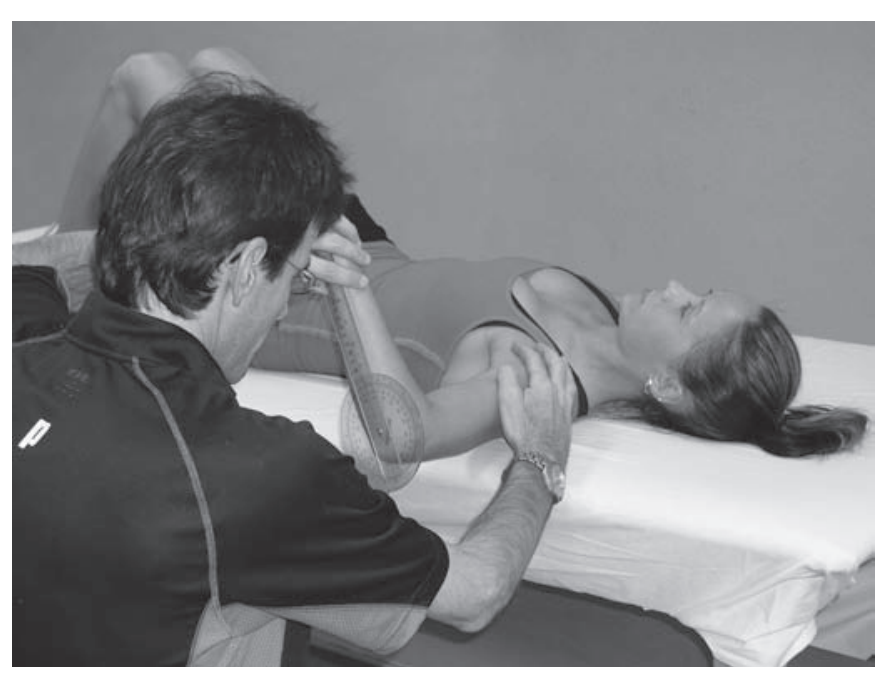

Figure 1 Technique used to measure more isolated glenohumeral joint internal rotation with the shoulder in $90^{\circ}$ of abduction in the coronal plane.

joint rotation. ${ }^{25}$ In addition, Crockett et a ${ }^{23}$ and others ${ }^{26} 27$ have shown unilateral increases in humeral retroversion in throwing athletes, which would explain the increase in external rotation with accompanying internal rotation loss.

Loss of internal rotation ROM is significant for several reasons. The relationship between internal rotation ROM loss (tightness in the posterior capsule of the shoulder) and increased anterior humeral head translation has been documented. ${ }^{28} 29$ The increase in anterior humeral shear force reported by Harryman et $a^{30}$ was manifested by a horizontal adduction cross-body manoeuvre, similar to that incurred during the follow-through of the throwing motion or tennis serve. Tightness of the posterior capsule has also been linked to increased superior migration of the humeral head during shoulder elevation. ${ }^{31}$

Recent research 3233 that studied the effects of posterior capsular tightness in a functional position of $90^{\circ}$ of abduction and $90^{\circ}$ or more of external rotation found that imbrication of either the inferior aspect of the posterior capsule or of the entire posterior capsule changed humeral head kinematics. In the presence of posterior capsular tightness, the humeral head shifted in an anterior superior direction, as compared with a normal shoulder with normal capsular relationships. With more extensive amounts of posterior capsular tightness, the humeral head was found to shift posterosuperiorly.

Accurate ROM measurement is crucial because a large spectrum of mobility can be encountered when treating the patient with rotator cuff pathology. Figures 2 and 3 show versions of clinical internal rotation stretching positions both of which utilise the scapular plane and can be performed in multiple and varied positions of glenohumeral abduction. Each inherently possesses an anterior hand placement used to give varying degrees of posterior pressure to minimise scapular compensation and also to provide a check rein against anterior humeral head translation during the internal rotation stretch. These stretches can be used in a proprioceptive neuromuscular facilitation contract-relax format or following a low-load prolonged stretch-type paradigm to facilitate the increase in ROM. ${ }^{34}$ 35 Figures 4 and 5 are examples of home stretches given to patients to address internal rotation ROM deficiency. Note the inherent methods of scapular stabilisation (body weight in the sleeper stretch and wall or firm object in the cross-body stretch) in both methods, which are necessary to optimise the value of the stretching procedure. 


\section{SCAPULAR STABILISATION}

Since the first clinical papers in the literature regarding the role of the scapula in athletic shoulder function and the possible relation to shoulder pain in the overhead athlete, ${ }^{12} 3637$ there has been growing interest in scapular kinematics, scapular evaluation and intervention principles and programmes. The association between abnormal scapular positions and motions and glenohumeral joint pathology has been well established in the literature. ${ }^{38-45}$ There is a body of evidence suggesting that patients with impingement symptoms and rotator cuff disease consistently show altered scapular kinematics, which is termed 'scapular dyskinesis'.

Scapular dyskinesis is generally characterised by a lack of upward rotation, a lack of posterior tilting and increased internal or medial rotation of the scapula. ${ }^{38} 3941-44$ These changes in scapular kinematics, in the resting position as well as during dynamic arm movements, have been attributed not only to altered recruitment patterns and muscle performance in the scapular stabilising muscles, ${ }^{38} 46-51$ but also to flexibility deficits in the soft tissue surrounding the scapula, possibly restricting normal scapular movement during daily activity and sport-specific movements. ${ }^{12} 52-55$

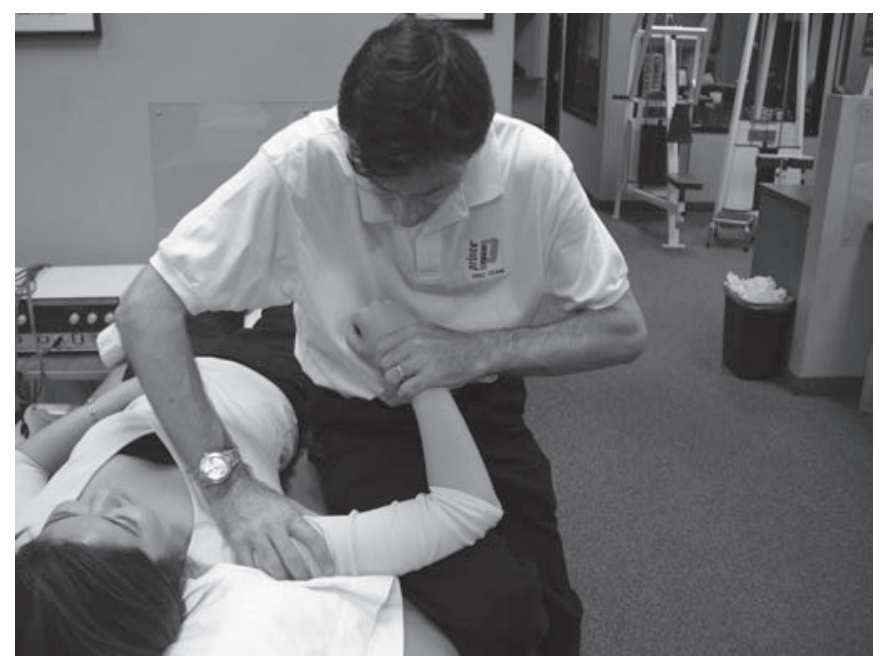

Figure 2 Internal rotation stretch using therapist's leg as a stabilising platform to allow both hands to control glenohumeral internal rotation and utilise the scapular plane.

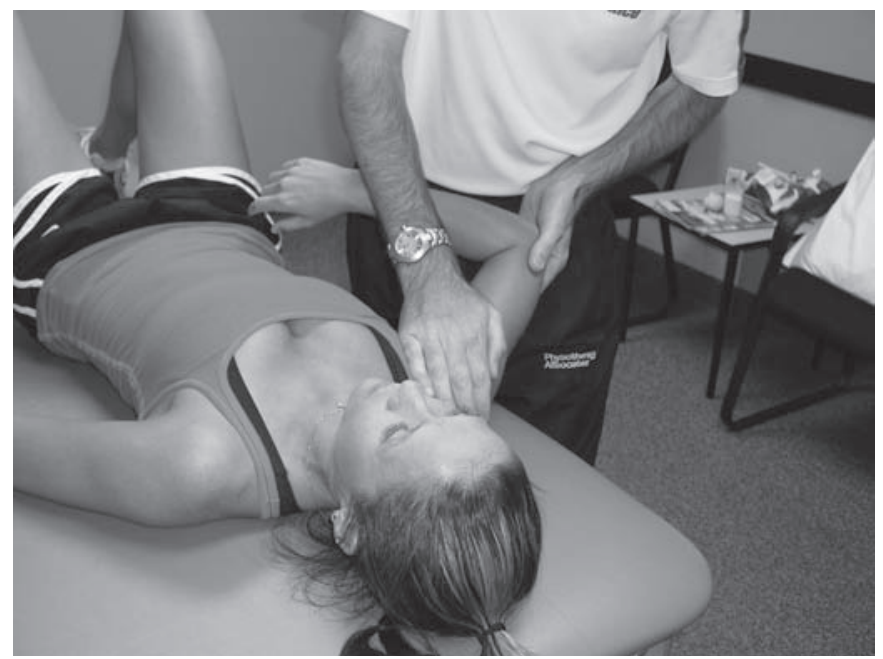

Figure 3 Figure 4 internal rotation stretch. Hand placements allow for containment of humeral translation and scapular compensation.
Several authors have demonstrated altered muscle activity patterns in the scapular muscles in patients with shoulder impingement. These include decreased muscular activity or

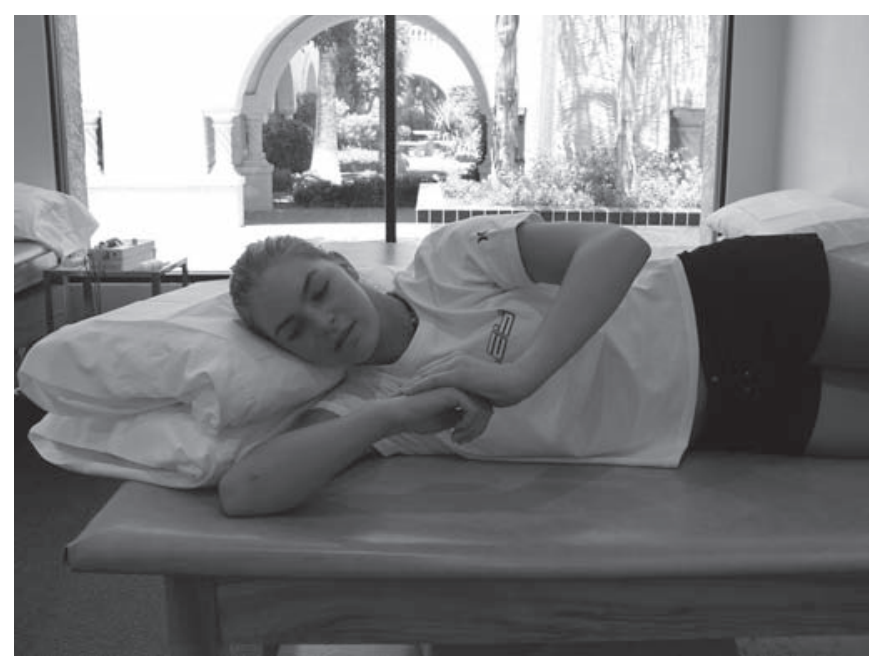

Figure 4 Sleeper stretch used as a home programme activity for patients with limited internal rotation range of motion.

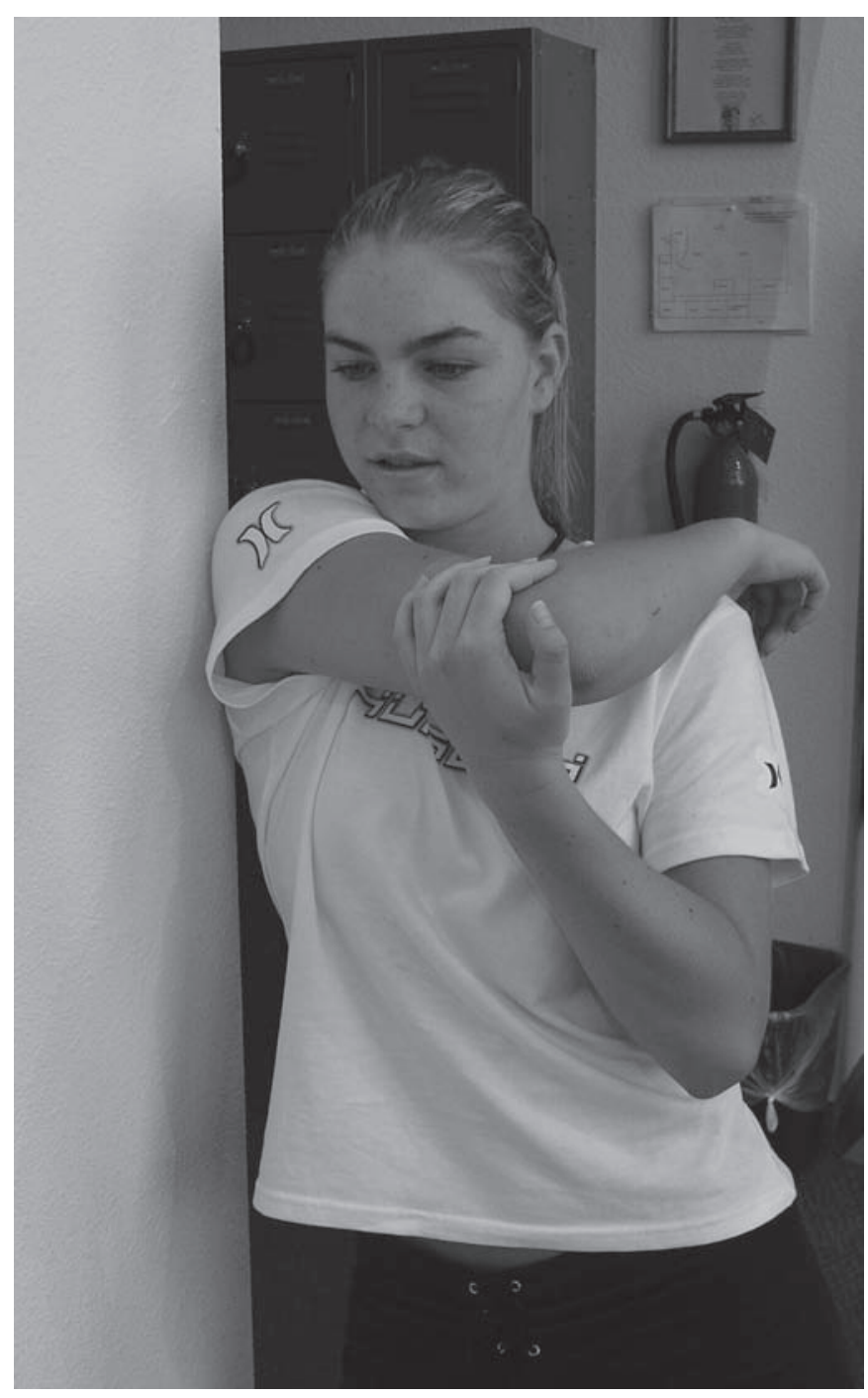

Figure 5 Cross arm stretch using the wall for additional scapular stabilisation to improve internal rotation range of motion. 
strength, and changes in the timing properties of the serratus anterior, the lower and middle portions of the trapezius, and increased activity in the upper part of the trapezius. ${ }^{38} 46-51$ Although some of the above-mentioned studies were performed on non-athletic populations, ${ }^{384344}$ many of the possible causes for scapular dyskinesis have been established in overhead athletes, ${ }^{41} 46-4951$ and have been suggested to be a contributing and perpetuating factor in the development of impingement symptoms in athletes performing overhead sports. ${ }^{125657}$

With respect to soft tissue inflexibility, tightness of the pectoralis minor and posterior glenohumeral capsular stiffness have been established in relation to abnormal scapular position. Borstad and Ludewig ${ }^{53}$ and Borstad ${ }^{54}$ demonstrated increased scapular internal rotation in subjects with a short pectoralis minor, as well as increased anterior tilting. In a study by Borich et al, ${ }^{52}$ subjects with posterior shoulder tightness (evaluated by measuring glenohumeral internal rotation ROM) demonstrated greater scapular anterior tilt. However, those studies from both authors were performed on healthy subjects. The association of these flexibility deficits, scapular kinematics and impingement-related shoulder pain should be further explored in overhead athletes with throwing-related shoulder pain. In addition, tightness of other structures possibly altering scapular kinematics and increasing the risk of shoulder impingement, such as the levator scapulae, latissimus dorsi and the rhomboids, have not been quantified in the overhead athlete, but could possibly contribute to motion restriction of the scapula and throwing-related secondary impingement, based on scapular dyskinesis.

In the therapist's decision-making and clinical reasoning process, a thorough clinical examination should precede the choice of treatment goals and appropriate techniques and exercises. In particular, evaluation of scapular dyskinesis should be performed using reliable and valid observation techniques and additional scapular tests. McClure et al ${ }^{58}$ and Tate et $a^{59}$ proposed a clinical examination protocol to evaluate scapular dysfunction, easily applicable by the clinician. In addition, scapular tests were developed and validated. The scapular assistance test 42575860 and the scapular retraction/ reposition test ${ }^{61} 62$ may help the clinician in defining the degree of scapular involvement in the actual shoulder complaints. Kibler et al63 defined three types of scapular dyskinesis, based on the rotational position of the scapula. Type I is increased anterior tilting, type II is increased internal rotation and type III is increased downward rotation. This method of visual observation of scapular evaluation resulted in moderate reliability and validity. A modification of this observational method combining all three types into a 'yes' (dyskinesis present)/'no' (none of the types seen) method resulted in higher sensitivity and positive predictive value. ${ }^{64}$ From those studies, we believe that qualitative analysis of scapular malpositioning and classification into subtypes based on observation is relevant from a clinical point of view, helping the therapist in choosing the appropriate treatment goals, based on the particular position and movement disorder. Therefore, we suggest the use of these subtypes in a clinical setting; however, the classification system may have greater limitations in a research setting.

Figure 6 summarises a clinical reasoning algorithm the clinician may use in the treatment of scapular dyskinesis. Flexibility deficits need to be addressed by stretching and mobilisation techniques, whereas muscle recruitment normalisation is the main goal for the patient who has muscle performance problems.

\section{Scapular Rehabilitation Algorithm}
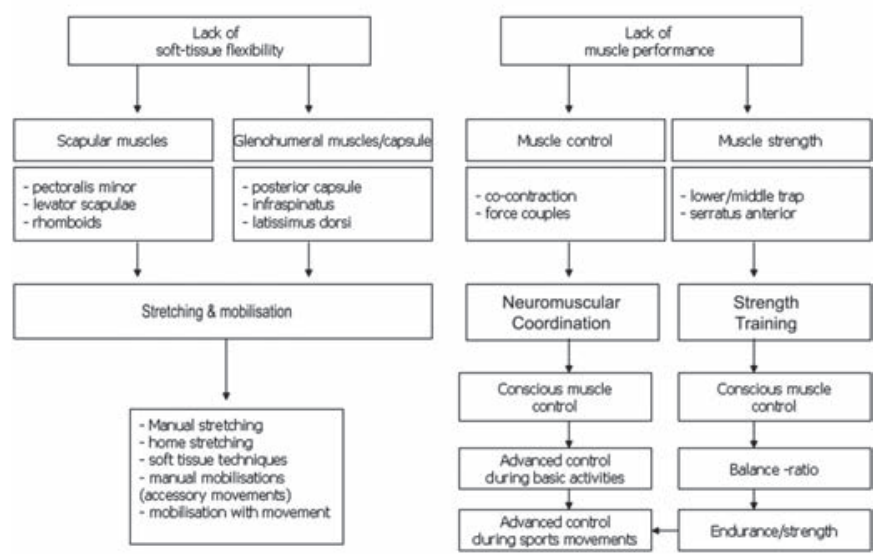

Figure 6 Treatment algorithm for scapular dysfunction.

Several stretches have been described to increase pectoralis minor length. ${ }^{65-67}$ Borstad and Ludewig ${ }^{67}$ showed superior effects of the 'unilateral corner stretch' (performing passive horizontal abduction with the shoulder in $90^{\circ}$ of abduction and external rotation) over 'sitting manual stretching' (in which the therapist performs scapular retraction with the shoulder in a neutral position) and 'supine manual stretch' (similar to the unilateral corner stretch, but performed by the therapist with the patient in a supine position). However, in our opinion, these stretches (with the exception of the 'sitting manual stretching') put the athlete's shoulder into a position, possibly causing pain in the case of subacromial or internal impingement. ${ }^{56869}$ In addition, it was found in a cadaveric study that performing retraction in a $30^{\circ}$ forward flexion position results in the largest changes in pectoralis minor length. ${ }^{66}$ Therefore, we suggest performing passive retraction and posterior tilting of the scapula with the shoulder in a neutral elevation position and slight external rotation (figure 7).

In view of the new insights and research findings on the role of the scapula in shoulder pathology, current exercise protocols emphasise the importance of scapular muscle training as an essential component of shoulder rehabilitation.. ${ }^{5670}$ In the early stage of scapular training, conscious muscle control of the scapular muscles may be necessary to improve proprioception and to normalise the scapular resting position. In order to activate the lower trapezius selectively, the 'scapular orientation exercise' has been described. ${ }^{37} 71$ This exercise is described as scapular setting in a variety of postures initially with the arm at the side placing the scapula in a mid-range position of upward/downward rotation, internal/external rotation and anterior posterior tilting. ${ }^{371}$ The authors demonstrated in their study ${ }^{71}$ that it is possible to teach a normal individual consistently to reproduce movements of the scapula into posterior tilt and upward rotation. In addition, this exercise resulted in a significant increase in scapular muscle activity, and a high correlation between assisted and unassisted exercise was established, indicating that an individual is able to perform this exercise in a home programme. Other researchers ${ }^{72-74}$ focused on the use of electromyographic feedback for learning selective activation of the serratus anterior ${ }^{74}$ and the effect of motor control and movement training on upper limb motor strategies and shoulder function. ${ }^{72} 73$ Roy and colleagues ${ }^{72} 73$ showed that conscious movement training with feedback causes immediate, but temporary, effects on motor strategies and upper limb kinematics. ${ }^{73}$ They also 


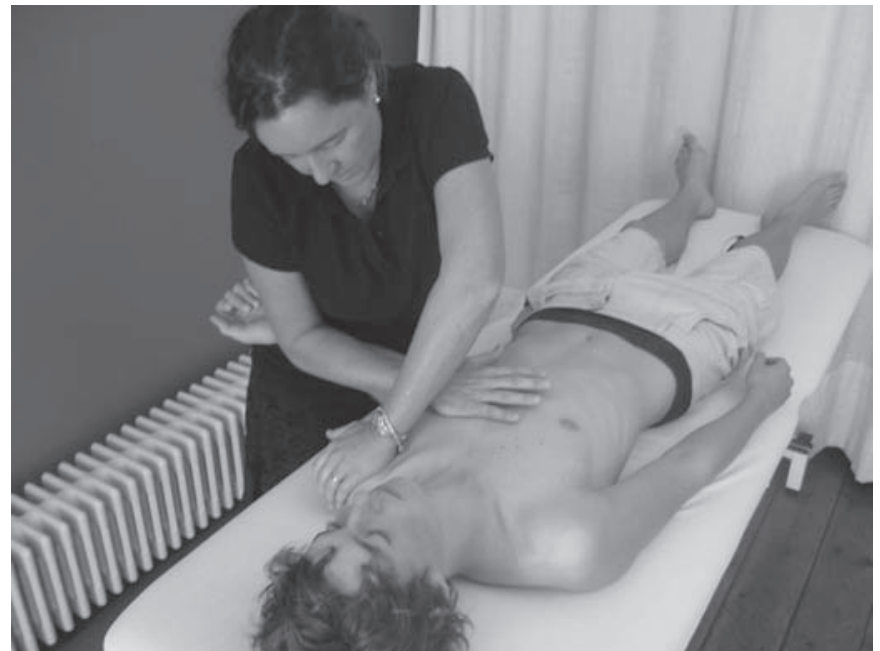

Figure 7 Cools scapular exercise.

showed that patients with impingement benefit from a 4-week motor control training programme to reduce pain and improve function. ${ }^{72}$ In summary, there is some preliminary evidence to support the use of conscious muscle control exercises to restore the force-couple activation in the scapular muscles, with special attention to activation of the lower trapezius and serratus anterior.

Depending on the results of the clinical examination, the therapist may decide in the second stage of scapular muscle training to focus more on muscle control (appropriate co-activation of the scapular force couples) or muscle strength (in case, for instance, manual muscle testing or isokinetic testing shows isolated strength deficit in one or more scapular muscles).

Following the scapular orientation exercises, scapular cocontraction may be exercised in basic positions, movements and exercises. Kibler and colleagues ${ }^{75} 76$ described specific exercises for scapular control in the early phases of shoulder rehabilitation. The 'low row', 'inferior glide', 'lawnmower' and 'robbery' exercises, as described in their paper, ${ }^{75}$ activate the key scapular-stabilising muscles without putting high demands on the shoulder joint, making these exercises appropriate to use in the early stages of non-operative as well as in postoperative rehabilitation. In addition to these basic exercises, the athlete may gradually perform functional diagonals into internal and external rotation with increasing intensity and load and accurate scapular muscle control, in preparation of the third stage of scapular muscle rehabilitation.

For patients with a strength deficit and muscle imbalance in the scapular muscles, selective activation of the weaker muscle parts with minimal activity of the hyperactive muscles is an important component in the second stage of scapular muscle rehabilitation. Because of the observed lack of activity in the lower trapezius and serratus anterior, 3848 often combined with excessive use of upper trapezius ${ }^{38} 4748$ exercises with low upper trapezius/lower trapezius, upper trapezius/middle trapezius and uppper trapezius/serratus anterior ratios are of particular importance. Several studies have been performed identifying exercises that meet this standard of favourable inter and intramuscular activation balance, in open as well as in closed kinetic chain, ${ }^{77-84}$ and several clinical papers extensively describe these exercises. ${ }^{5685}$ In a recent study by De Mey et al, ${ }^{78}$ it was demonstrated that exercises with optimal upper trapezius/middle trapezius and upper trapezius/lower trapezius ratios in terms of activity level ${ }^{77}$ also guarantee early activation of the lower trapezius and inhibition of the latency of the upper trapezius. Another way to increase muscle activity in the weaker muscles is by integrating kinetic chain components into the exercise. Maenhout et a ${ }^{83}$ investigated the influence of lower extremity position on muscle activity and balance during push-up variations, and revealed increased activity in the serratus anterior if the ipsilateral leg was extended, whereas extension of the contralateral leg improved lower trapezius activity. Also, in open chain low rowing exercises, unilateral stance on the contralateral leg increased scapular muscle activity and improved the upper trapezius/lower trapezius ratio, whereas sitting positions and bilateral stance seem not to be favourable for optimal scapular muscle balance (De Mey et al, unpublished data).

Once muscle balance is restored, in the third stage of scapular muscle rehabilitation, general scapular strengthening exercises may be used to increase muscle strength. Numerous studies propose optimal strengthening exercises for the scapular muscles, ${ }^{80} 85-88$ and a detailed description of these exercises goes beyond the scope of this paper. In this last stage of scapular rehabilitation, in which the treatment goal is to exercise advanced scapular muscle control and strength during sportspecific movements, special attention is given to integration of the kinetic chain into the exercise programme, ${ }^{568389}$ implementation of sport-specific demands by performing plyometric exercises ${ }^{90}$ and eccentric exercises. ${ }^{9192}$

\section{ROTATOR CUFF STRENGTHENING}

The use of specific techniques to quantify muscular strength and most importantly muscular balance in the patient with rotator cuff pathology is indicated. Objective studies using instrumented testing of the rotator cuff consistently show both weakness and muscular imbalance of the external and internal rotator muscles on the injured extremity in patients with rotator cuff impingement and glenohumeral joint instability. ${ }^{93}$ In a detailed study of electromyographic activity of the rotator cuff and deltoid musculature in normal subjects and patients with shoulder impingement, significant decreases in supraspinatus and infraspinatus activity in subjects with impingement were found. ${ }^{94}$ Several studies have measured the concentric external rotators/internal rotators ratio using isokinetic dynamometry in healthy uninjured subjects and found this ratio to be approximately $60-70 \%{ }^{95-99}$ in most positions of testing, including $0^{\circ}$ and $90^{\circ}$ of abduction in the scapular plane. Therefore, evaluating the relative strength and/or unilateral muscle strength ratio (ie, concentric external rotators/ internal rotators ratio) will help to direct the emphasis in the rehabilitation resistive exercise programme. ${ }^{95}$

\section{RESISTIVE EXERCISE PROGRESSION TO PROMOTE MUSCULAR BALANCE}

The primary goals of these programmes are to elicit high levels of rotator cuff and scapular muscular activation using movement patterns and positions that do not create significant subacromial contact or undue stress to the static stabilisers of the glenohumeral joint.

Sidelying external rotation and prone shoulder extension with an externally rotated (thumb out) position are typically utilised first, with progression to the prone horizontal abduction and prone external rotation exercises with scapular retraction following a demonstrated tolerance to the initial two exercises. Prone horizontal abduction is used at $90^{\circ}$ of abduction to minimise the effects from subacromial contact. Research has shown this position to create high levels 
of supraspinatus muscular activation 100101102103 making it an alternative to the widely used 'empty can' exercise, which can often cause impingement due to the combined inherent movements of internal rotation and elevation. ${ }^{105}$ The empty can exercise is no longer recommended in the rehabilitation of patients with rotator cuff pathology.

In general, three sets of 15-20 repetitions are recommended to create a fatigue response and target the development of local muscular endurance. ${ }^{105}$ Moncrief et al ${ }^{106}$ have demonstrated the efficacy of these exercises in a 4 -week training paradigm, and measured $8-10 \%$ increases in isokinetically measured internal and external rotation strength in healthy subjects. Niederbracht et al ${ }^{107}$ also reported significant gains in strength of the rotator cuff, specifically targeting external rotation strengthening to normalise external/internal rotation strength balance in a group of female overhead athletes.

These isotonic exercises can be coupled with a standing external rotation exercise with elastic tubing as well as the external rotation oscillation exercise, which uses 30 -s sets and elastic resistance to provide a resistance bias to the posterior rotator cuff using an oscillating device (figure 8). All exercises for external rotation strengthening in standing are performed with the addition of a small towel roll placed in the axilla, as pictured. In addition to assisting in the isolation of the exercise and controlling unwanted movements, this position of slight abduction has been shown to elevate muscular activity by $10 \%$ in the infraspinatus muscle when compared with identical rotational exercises performed in adduction. ${ }^{102}$ Other advantages of the use of a towel roll or pillow to place the shoulder in approximately $20-30^{\circ}$ of abduction are preventing decreased

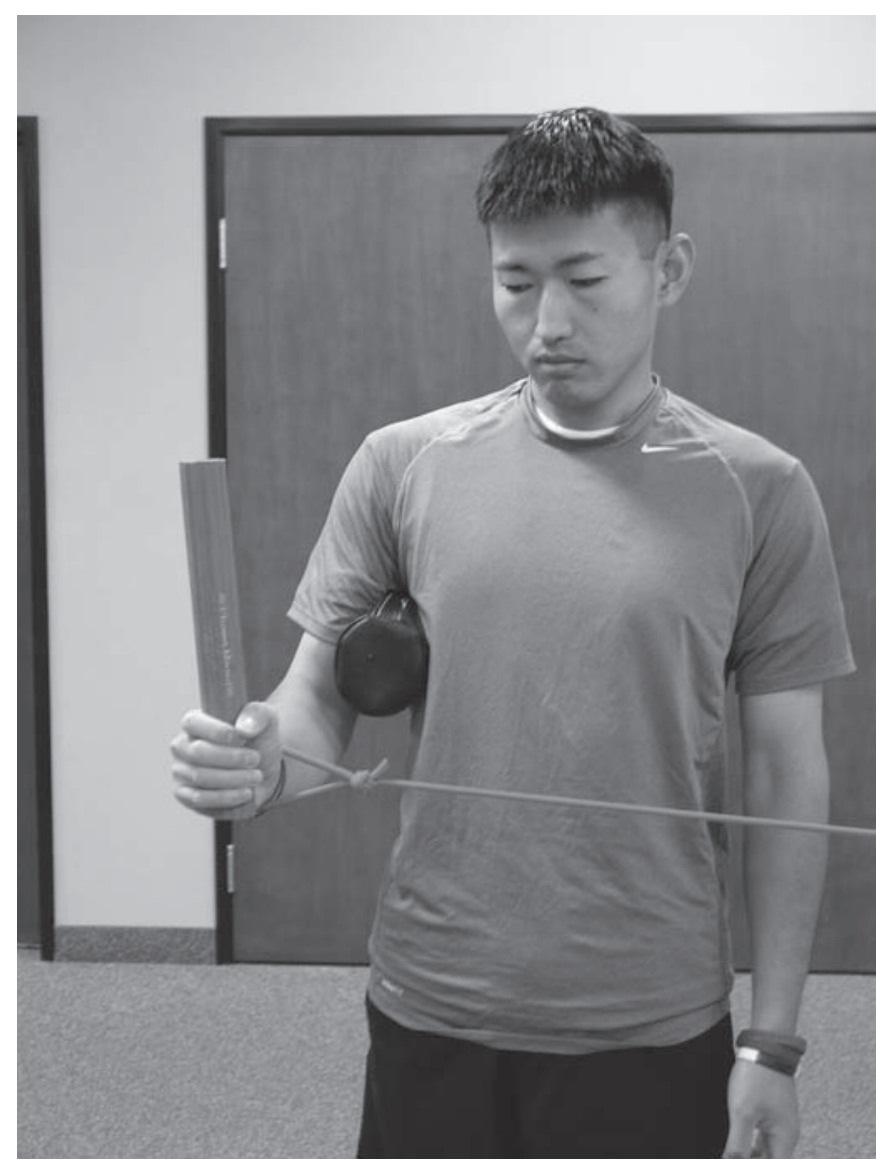

Figure 8 External rotation oscillation. blood flow in the supraspinatus tendon ${ }^{108}$ and increasing the subacromial space. ${ }^{109}$

One of the other key aspects of any resistive exercise programme is exercise load or intensity. Bitter et al $l^{110}$ have reported the inherent advantages of using low-resistance exercise strategies to target the infraspinatus during external rotation exercise. They report specifically on external rotation exercise using a $40 \%$ maximal voluntary isometric contraction to be superior to higher loads in preferentially recruiting the infraspinatus muscle over conditions with higher maximal voluntary isometric contraction loading, because increased loading leads to a relative increase in the amount of middle deltoid muscle activation.

Progression to exercises that more appropriately simulate the function of the rotator cuff during overhead activities is warranted upon successful tolerance of the initial rotator cuff exercise programme outlined above. ${ }^{111}$ Exercises using $90^{\circ}$ of glenohumeral joint abduction and the scapular plane serve to apply the specificity principle to middle-stage rehabilitation and prepare the athletic patient for the positions used during a return to both throwing ${ }^{112}$ and serving based on biomechanical research. In addition to traditional external rotation exercise in the scapular plane elevated position, the use of both oscillation and rhythmic stabilisation or perturbations applied by the clinician can be used to add additional challenges to the exercise and increase the number of repetitions applied in the exercise session (figure 9).

Finally, the use of isokinetic exercise, initially in the modified base position, which is characterised by the glenohumeral joint elevated $20-30^{\circ}$ in the scapular plane position 9596 and progressing to $90^{\circ}$ abducted training, has been shown to increase multiple parameters of muscle function ${ }^{113}$ 114 and also to improve functional performance. Multiple sets of $15-20$ repetitions are applied using the isokinetic dynamometer focusing on faster, more functional contractile velocities (speeds) and using load ranges similar to those used during functional activities. Plyometric exercises for the posterior rotator cuff in overhead athletes are also used in the later stages of rehabilitation in the $90 / 90$ position (figure 10). Descriptive reports of electromyographic activity in the rotator cuff and scapular musculature have demonstrated favourable activation of these important muscles using 0.5 and $1 \mathrm{~kg}$ medicine balls, with improvements in both concentric and eccentric rotator cuff strength following an 8-week training

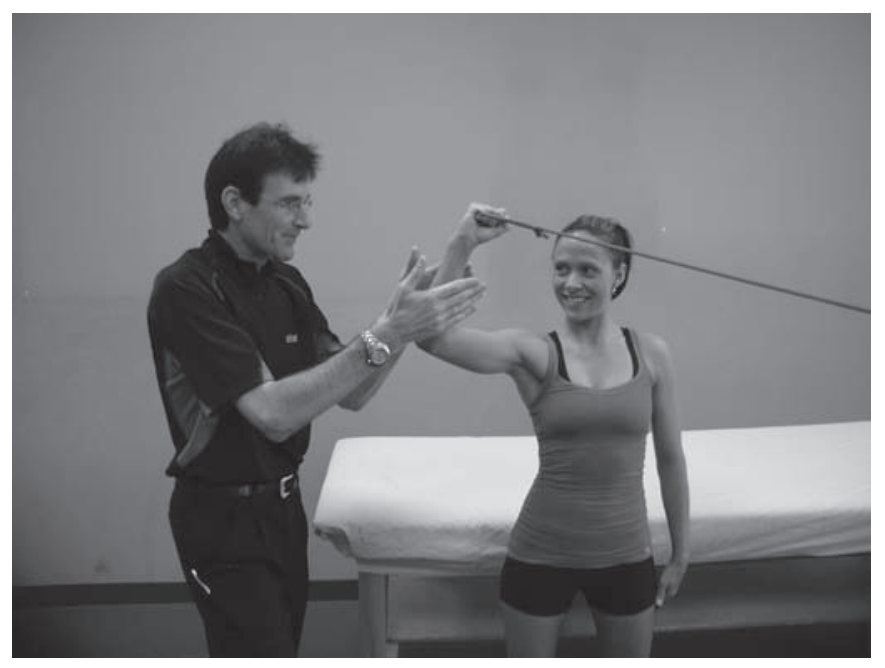

Figure 9 Perturbations applied to the patient's extremity in the 90/90 position using the scapular plane. 


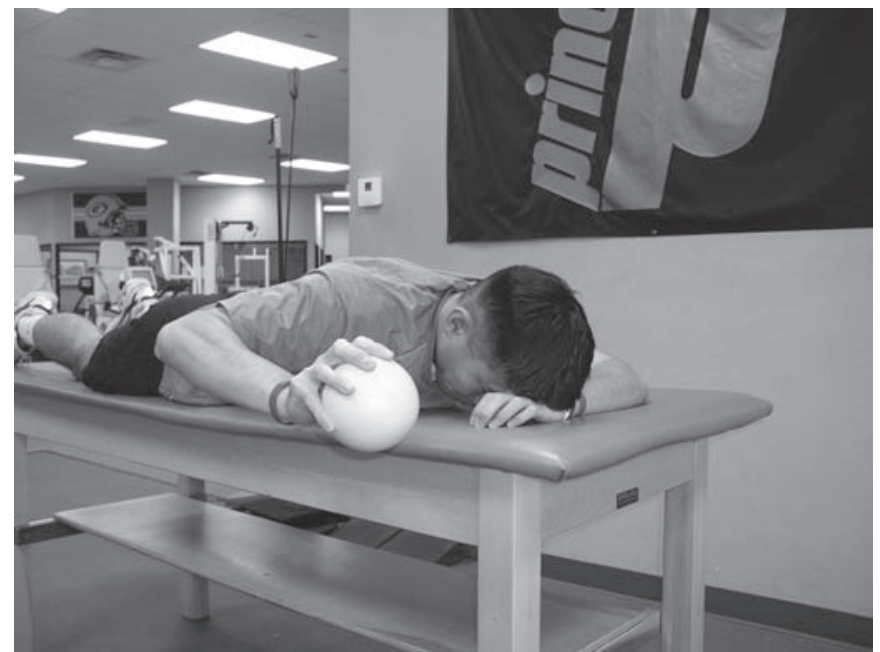

Figure 10 Prone 90/90 plyometric exercise for posterior rotator cuff and scapular training.

period of plyometric and elastic-based rotator cuff exercise in baseball players.

Each of these exercise progressions for the rotator cuff is applied with the goal of improving strength and local muscular endurance. Frequent monitoring of muscular performance with specific emphasis on the muscle balance between the external and internal rotators is recommended and followed to guide the continued evidence-based selection of exercise for the patient undergoing rehabilitation for rotator cuff pathology. Patients ultimately progress towards levels of bilateral symmetry in muscular strength and established muscular strength ratios. The emphasis and relative success of resistive exercise programmes for the rotator cuff and scapular musculature has been outlined in a systematic review of shoulder impingement by Kuhn. ${ }^{115}$

\section{What is known about this topic}

- Due to a greater understanding of the anatomy and biomechanics of the shoulder and the impingement process gained through basic science research, clinicians can better understand the key structures involved, and the mechanism by which impingement occurs in the human shoulder.

\section{What this paper adds}

- This paper provides a summary of key interventions used to treat shoulder impingement. This review details clinical exercises and their inherent objective muscular activity characteristics to guide clinicians in the development of individualised rehabilitation programmes for treatment of the patient with shoulder impingement.

\section{CONCLUSION}

The integration of key physical examination techniques with evidence-driven rehabilitation concepts to restore optimal ROM and rotator cuff and scapular strength and stabilisation forms the basis of clinical rehabilitation of the athlete with rotator cuff impingement. The continued application of basic science research, clinical training and outcomes research will provide additional insight and guidelines for treating impingement in the athletic shoulder.

\section{Competing interests None.}

Provenance and peer review Commissioned; not externally peer reviewed.

Detail has been removed from these case descriptions to ensure anonymity. The editors and reviewers have seen the detailed information available and are satisfied that the information backs up the case the authors are making.

\section{REFERENCES}

1. Neer CS I. Anterior acromioplasty for the chronic impingement syndrome in the shoulder: a preliminary report. J Bone Joint Surg Am 1972;54:41-50.

2. Neer CS II. Impingement lesions. Clin Orthop Relat Res 1983;173:70-7.

3. Golding FC. The shoulder - the forgotten joint. Br J Radiol 1962;35:149-58.

4. Cotton RE, Rideout DF. Tears of the humeral rotator cuff; a radiological and pathological necropsy survey. J Bone Joint Surg Br 1964;46:314-28.

5. Jobe $\mathbf{F W}$, Kvitne RS, Giangarra CE. Shoulder pain in the overhand or throwing athlete. The relationship of anterior instability and rotator cuff impingement. Orthop Rev 1989;18:963-75.

6. Walch G, Boileau P, Noel E, et al. Impingement of the deep surface of the supraspinatus tendon on the posterosuperior glenoid rim: an arthroscopic study. $J$ Shoulder Elbow Surg 1992;1:238-45.

7. Paley KJ, Jobe FW, Pink MM, et al. Arthroscopic findings in the overhand throwing athlete: evidence for posterior internal impingement of the rotator cuff. Arthroscopy 2000;16:35-40.

8. McFarland EG, Torpey BM, Curl LA. Evaluation of shoulder laxity. Sports Med 1996;22:264-72.

9. Gerber C, Ganz R. Clinical assessment of instability of the shoulder. With special reference to anterior and posterior drawer tests. J Bone Joint Surg Br 1984;66:551-6.

10. Hamner DL, Pink MM, Jobe FW. A modification of the relocation test: arthroscopic findings associated with a positive test. J Shoulder Elbow Surg 2000;9:263-7.

11. Beighton $\mathbf{P}$, Horan F. Orthopaedic aspects of the Ehlers-Danlos syndrome. $J$ Bone Joint Surg Br 1969;51:444-53.

12. Kibler WB. The role of the scapula in athletic shoulder function. Am J Sports Med 1998;26:325-37.

13. Wilk KE, Obma P, Simpson CD, et al. Shoulder injuries in the overhead athlete. $J$ Orthop Sports Phys Ther 2009;39:38-54.

14. Ellenbecker TS. Shoulder rehabilitation: non operative treatment. New York, USA: Thieme, 2006

15. Johnson AJ, Godges JJ, Zimmerman GJ, et al. The effect of anterior versus posterior glide joint mobilization on external rotation range of motion in patients with shoulder adhesive capsulitis. J Orthop Sports Phys Ther 2007;37:88-99.

16. Awan R, Smith J, Boon AJ. Measuring shoulder internal rotation range of motion: a comparison of 3 techniques. Arch Phys Med Rehabil 2002;83:1229-34.

17. Boon AJ, Smith J. Manual scapular stabilization: its effect on shoulder rotational range of motion. Arch Phys Med Rehabil 2000;81:978-83.

18. Ellenbecker TS, Roetert EP, Piorkowski PA, et al. Glenohumeral joint internal and external rotation range of motion in elite junior tennis players. J Orthop Sports Phys Ther 1996;24:336-41.

19. Ellenbecker TS, Roetert EP, Bailie DS, et al. Glenohumeral joint total rotation range of motion in elite tennis players and baseball pitchers. Med Sci Sports Exerc 2002;34:2052-6.

20. Ellenbecker TS. Shoulder internal and external rotation strength and range of motion in highly skilled tennis players. Isokinet Exerc Sci 1992;2:1-8.

21. Brown LP, Niehues SL, Harrah A, et al. Upper extremity range of motion and isokinetic strength of the internal and external shoulder rotators in major league baseball players. Am J Sports Med 1988;16:577-85.

22. Ellenbecker TS, Roetert EP, Piorkowski PA. Shoulder internal and external rotation range of motion of elite junior tennis players: a comparison of two protocols. J Orthop Sports Phys Ther 1993;17:65

23. Crockett HC, Gross LB, Wilk KE, et al. Osseous adaptation and range of motion at the glenohumeral joint in professional baseball pitchers. Am J Sports Med 2002;30:20-6.

24. Meister K, Day T, Horodyski M, et al. Rotational motion changes in the glenohumeral joint of the adolescent/Little League baseball player. Am J Sports Med 2005;33:693-8. 
25. Reisman S, Walsh LD, Proske U. Warm-up stretches reduce sensations of stiffness and soreness after eccentric exercise. Med Sci Sports Exerc 2005;37:929-36.

26. Reagan KM, Meister K, Horodyski MB, et al. Humeral retroversion and its relationship to glenohumeral rotation in the shoulder of college baseball players. Am J Sports Med 2002;30:354-60.

27. Osbahr DC, Cannon DL, Speer KP. Retroversion of the humerus in the throwing shoulder of college baseball pitchers. Am J Sports Med 2002;30:347-53.

28. Tyler TF, Nicholas SJ, Roy T, et al. Quantification of posterior capsule tightness and motion loss in patients with shoulder impingement. Am J Sports Med 2000;28:668-73.

29. Gerber C, Werner CM, Macy JC, et al. Effect of selective capsulorrhaphy on the passive range of motion of the glenohumeral joint. J Bone Joint Surg Am 2003;85-A:48-55

30. Harryman DT II, Sidles JA, Clark JM, et al. Translation of the humeral head on the glenoid with passive glenohumeral motion. J Bone Joint Surg Am 1990;72:1334-43

31. Matsen FA III, Artnz CT. Subacromial impingement. In: Rockwood CA Jr, Matsen FA III, eds. The shoulder. Philadelphia, Pennsylvania, USA: WB Saunders, 1990.

32. Koffler KM, Bader D, Eager M, et al. The effect of posterior capsular tightness on glenohumeral translation in the late-cocking phase of pitching: a cadaveric study. Abstract (SS-15) presented at Arthroscopy Association of North America Annual Meeting, Washington, DC, 2001

33. Grossman MG, Tibone JE, McGarry MH, et al. A cadaveric model of the throwing shoulder: a possible etiology of superior labrum anterior-to-posterior lesions. $J$ Bone Joint Surg Am 2005;87:824-31.

34. Sullivan PE, Markos PD, Minor MD. An integrated approach to therapeutic exercise: theory \& clinical application. Reston, Virginia, USA: Reston Publishing Co, 1982.

35. Zachezewski JE, Reischl S. Flexibility for the runner: specific program considerations. Topics Acute Care Trauma Rehab 1986;1:9-27.

36. Kamkar A, Irrgang JJ, Whitney SL. Nonoperative management of secondary shoulder impingement syndrome. J Orthop Sports Phys Ther 1993;17:212-24.

37. Mottram SL. Dynamic stability of the scapula. Man Ther 1997;2:123-31.

38. Ludewig PM, Cook TM. Alterations in shoulder kinematics and associated muscle activity in people with symptoms of shoulder impingement. Phys Ther 2000;80:276-91.

39. Endo K, Ikata T, Katoh $\mathrm{S}$, et al. Radiographic assessment of scapular rotational tilt in chronic shoulder impingement syndrome. J Orthop Sci 2001;6:3-10.

40. Hébert LJ, Moffet H, McFadyen BJ, et al. Scapular behavior in shoulder impingement syndrome. Arch Phys Med Rehabil 2002;83:60-9

41. Laudner KG, Myers JB, Pasquale MR, et al. Scapular dysfunction in throwers with pathologic internal impingement. J Orthop Sports Phys Ther 2006; 36:485-94.

42. Ludewig PM, Reynolds JF. The association of scapular kinematics and glenohumeral joint pathologies. J Orthop Sports Phys Ther 2009;39:90-104.

43. Lukasiewicz AC, McClure P, Michener L, et al. Comparison of 3-dimensional scapular position and orientation between subjects with and without shoulder impingement. J Orthop Sports Phys Ther 1999;29:574-83; discussion 584-6.

44. McClure PW, Michener LA, Karduna AR. Shoulder function and 3-dimensional scapular kinematics in people with and without shoulder impingement syndrome. Phys Ther 2006;86:1075-90.

45. Warner JJ, Micheli LJ, Arslanian LE, et al. Scapulothoracic motion in normal shoulders and shoulders with glenohumeral instability and impingement syndrome. A study using Moire topographic analysis. Clin Orthop Relat Res 1992:285:191-9.

46. Cools AM, Witvrouw EE, Declercq GA, et al. Scapular muscle recruitment patterns: trapezius muscle latency with and without impingement symptoms. Am J Sports Med 2003;31:542-9.

47. Cools AM, Declercq GA, Cambier DC, et al. Trapezius activity and intramuscular balance during isokinetic exercise in overhead athletes with impingement symptoms. Scand J Med Sci Sports 2007:17:25-33.

48. Cools AM, Witvrouw EE, Declercq GA, et al. Evaluation of isokinetic force production and associated muscle activity in the scapular rotators during a protraction-retraction movement in overhead athletes with impingement symptoms. Br J Sports Med 2004;38:64-8.

49. Cools AM, Witvrouw EE, Mahieu NN, et al. Isokinetic scapular muscle performance in overhead athletes with and without impingement symptoms. $J$ Athl Train 2005;40:104-10

50. Moraes GF, Faria CD, Teixeira-Salmela LF. Scapular muscle recruitment patterns and isokinetic strength ratios of the shoulder rotator muscles in individuals with and without impingement syndrome. J Shoulder Elbow Surg 2008;17:48S-53S

51. Wadsworth DJ, Bullock-Saxton JE. Recruitment patterns of the scapular rotator muscles in freestyle swimmers with subacromial impingement. Int J Sports Med 1997;18:618-24.

52. Borich MR, Bright JM, Lorello DJ, et al. Scapular angular positioning at end range internal rotation in cases of glenohumeral internal rotation deficit. J Orthop Sports Phys Ther 2006;36:926-34.
53. Borstad JD, Ludewig PM. The effect of long versus short pectoralis minor resting length on scapular kinematics in healthy individuals. J Orthop Sports Phys Ther 2005;35:227-38.

54. Borstad JD. Resting position variables at the shoulder: evidence to support a posture-impairment association. Phys Ther 2006:86:549-57.

55. Borstad JD, Mathiowetz KM, Minday LE, et al. Clinical measurement of posterior shoulder flexibility. Man Ther 2007;12:386-9.

56. Cools AM, Declercq G, Cagnie B, et al. Internal impingement in the tennis player: rehabilitation guidelines. Br J Sports Med 2008:42:165-71.

57. Burkhart SS, Morgan CD, Kibler WB. The disabled throwing shoulder: spectrum of pathology. Part III: The SICK scapula, scapular dyskinesis, the kinetic chain, and rehabilitation. Arthroscopy 2003;19:641-61.

58. McClure $\mathbf{P}$, Tate AR, Kareha S, et al. A clinical method for identifying scapular dyskinesis. Part 1: reliability. J Ath/ Train 2009;44:160-4.

59. Tate AR, McClure P, Kareha S, et al. A clinical method for identifying scapular dyskinesis. Part 2: validity. J Athl Train 2009;44:165-73.

60. Rabin A, Irrgang JJ, Fitzgerald GK, et al. The intertester reliability of the Scapular Assistance Test. J Orthop Sports Phys Ther 2006:36:653-60.

61. Kibler WB, Sciascia A, Dome D. Evaluation of apparent and absolute supraspinatus strength in patients with shoulder injury using the scapular retraction test. Am J Sports Med 2006;34:1643-7.

62. Tate AR, McClure PW, Kareha S, et al. Effect of the Scapula Reposition Test on shoulder impingement symptoms and elevation strength in overhead athletes. $J$ Orthop Sports Phys Ther 2008;38:4-11.

63. Kibler WB, Uhl TL, Maddux JW, et al. Qualitative clinical evaluation of scapular dysfunction: a reliability study. J Shoulder Elbow Surg 2002;11:550-6.

64. Uhl TL, Kibler WB, Gecewich B, et al. Evaluation of clinical assessment methods for scapular dyskinesis. Arthroscopy 2009;25:1240-8.

65. Muraki T, Aoki M, Izumi T, et al. Lengthening of the pectoralis minor muscle during passive shoulder motions and stretching techniques: a cadaveric biomechanical study. Phys Ther 2009;89:333-41.

66. Sciascia A, Kibler WB. The pediatric overhead athlete: what is the real problem? Clin J Sport Med 2006;16:471-7.

67. Borstad JD, Ludewig PM. Comparison of three stretches for the pectoralis minor muscle. J Shoulder Elbow Surg 2006;15:324-30.

68. Meister K, Buckley B, Batts J. The posterior impingement sign: diagnosis of rotator cuff and posterior labral tears secondary to internal impingement in overhand athletes. Am J Orthop 2004;33:412-15.

69. Gold GE, Pappas GP, Blemker SS, et al. Abduction and external rotation in shoulder impingement: an open MR study on healthy volunteers initial experience. Radiology 2007;244:815-22.

70. Uhl T, Kibler WB. The role of the scapula in rehabilitation. In: Wilk KE, Reinold MM, Andrews JR, eds. The athlete's shoulder. 2nd edn. Philadelphia, Pennsylvania, USA: Churchill Livingstone, 2009:671-84.

71. Mottram SL, Woledge RC, Morrissey D. Motion analysis study of a scapular orientation exercise and subjects' ability to learn the exercise. Man Ther 2009;14:13-18.

72. Roy JS, Moffet H, McFadyen BJ. Upper limb motor strategies in persons with and without shoulder impingement syndrome across different speeds of movement. Clin Biomech (Bristol, Avon) 2008;23:1227-36.

73. Roy JS, Moffet H, Hébert LJ, et al. Effect of motor control and strengthening exercises on shoulder function in persons with impingement syndrome: a singlesubject study design. Man Ther 2009;14:180-8.

74. Holtermann A, Mork PJ, Andersen LL, et al. The use of EMG biofeedback for learning of selective activation of intra-muscular parts within the serratus anterior muscle. A novel approach for rehabilitation of scapular muscle imbalance. $J$ Electromyogr Kinesiol 2010;20:359-65

75. Kibler WB, Sciascia AD, Uhl TL, et al. Electromyographic analysis of specific exercises for scapular control in early phases of shoulder rehabilitation. $A m J$ Sports Med 2008;36:1789-98.

76. Kibler WB. Shoulder rehabilitation: principles and practice. Med Sci Sports Exerc 1998; 30:S40-50

77. Cools AM, Dewitte V, Lanszweert F, et al. Rehabilitation of scapular muscle balance: which exercises to prescribe? Am J Sports Med 2007;35:1744-51.

78. De Mey K, Cagnie B, Danneels LA, et al. Trapezius muscle timing during selected shoulder rehabilitation exercises. J Orthop Sports Phys Ther 2009;39:743-52.

79. de Oliveira AS, de Morais Carvalho M, de Brum DP. Activation of the shoulder and arm muscles during axial load exercises on a stable base of support and on a medicine ball. J Electromyogr Kinesiol 2008:18:472-9.

80. Ekstrom RA, Donatelli RA, Soderberg GL. Surface electromyographic analysis of exercises for the trapezius and serratus anterior muscles. J Orthop Sports Phys Ther 2003:33:247-58.

81. Hardwick DH, Beebe JA, McDonnell MK, et al. A comparison of serratus anterior muscle activation during a wall slide exercise and other traditional exercises. J Orthop Sports Phys Ther 2006;36:903-10.

82. Ludewig PM, Hoff MS, Osowski EE, et al. Relative balance of serratus anterior and upper trapezius muscle activity during push-up exercises. Am J Sports Med 2004:32:484-93 
83. Maenhout AG, Pizzi L, Van Praet K, et al. Electromyographic analysis of knee push up plus variations: what is the influence of the kinetic chain on scapular muscle activity? Br J Sports Med. Published Online First. doi:10.1136/ bjsm.2009.062810.

84. Tucker WS, Campbell BM, Swartz EE, et al. Electromyography of 3 scapular muscles: a comparative analysis of the cuff link device and a standard push-up. $J$ Athl Train 2008;43:464-9.

85. Reinold MM, Escamilla RF, Wilk KE. Current concepts in the scientific and clinical rationale behind exercises for glenohumeral and scapulothoracic musculature. $J$ Orthop Sports Phys Ther 2009;39:105-17.

86. Decker MJ, Hintermeister RA, Faber KJ, et al. Serratus anterior muscle activity during selected rehabilitation exercises. Am J Sports Med 1999;27:784-91.

87. Hintermeister RA, Lange GW, Schultheis JM, et al. Electromyographic activity and applied load during shoulder rehabilitation exercises using elastic resistance. Am J Sports Med 1998;26:210-20

88. Moseley JB Jr, Jobe FW, Pink M, et al. EMG analysis of the scapular muscles during a shoulder rehabilitation program. Am J Sports Med 1992;20:128-34.

89. Kibler WB, Chandler TJ, Shapiro R, et al. Muscle activation in coupled scapulohumeral motions in the high performance tennis serve. Br J Sports Med 2007:41:745-9.

90. Wilk KE, Voight ML. Plyometrics for the shoulder complex. In: Wilk KE, Reinold MM, Andrews JR, eds. The athlete's shoulder. 2nd edn. Philadelphia, Pennsylvania, USA: Churchill Livingstone, 2009:749-61.

91. Myers JB, Pasquale MR, Laudner KG, et al. On-the-field resistancetubing exercises for throwers: an electromyographic analysis. J Athl Train 2005:40:15-22.

92. Carter AB, Kaminski TW, Douex AT Jr, et al. Effects of high volume upper extremity plyometric training on throwing velocity and functional strength ratios of the shoulder rotators in collegiate baseball players. J Strength Cond Res 2007;21:208-15

93. Erol 0, Ozçakar L, Celiker R. Shoulder rotator strength in patients with stage I-II subacromial impingement: relationship to pain, disability, and quality of life. $J$ Shoulder Elbow Surg 2008;17:893-7.

94. Reddy AS, Mohr KJ, Pink MM, et al. Electromyographic analysis of the deltoid and rotator cuff muscles in persons with subacromial impingement. J Shoulder Elbow Surg 2000;9:519-23.

95. Ellenbecker TS, Davies GJ. The application of isokinetics in testing and rehabilitation of the shoulder complex. J Athl Train 2000;35:338-50.

96. Davies GJ. A compendium of isokinetics in clinical usage. LaCrosse, Wisconsin, USA: S \& S Publishers, 1992.

97. Ivey FM Jr, Calhoun JH, Rusche K, et al. Isokinetic testing of shoulder strength: normal values. Arch Phys Med Rehabil 1985;66:384-6.

98. Cain PR, Mutschler TA, Fu FH, et al. Anterior stability of the glenohumeral joint. A dynamic model. Am J Sports Med 1987;15:144-8.
99. Ackland DC, Pak P, Richardson M, et al. Moment arms of the muscles crossing the anatomical shoulder. J Anat 2008;213:383-90.

100. Ballantyne BT, O'Hare SJ, Paschall JL, et al. Electromyographic activity of selected shoulder muscles in commonly used therapeutic exercises. Phys Ther 1993;73:668-77; discussion 677-82.

101. Blackburn TA, McLeod WD, White B, et al. EMG analysis of posterior rotator cuff exercises. Athl Train J Natl Athl Train Assoc 1990;25:40-5.

102. Reinold MM, Wilk KE, Fleisig GS, et al. Electromyographic analysis of the rotator cuff and deltoid musculature during common shoulder external rotation exercises. J Orthop Sports Phys Ther 2004;34:385-94.

103. Malanga GA, Jenp YN, Growney ES, et al. EMG analysis of shoulder positioning in testing and strengthening the supraspinatus. Med Sci Sports Exerc 1996;28:661-4.

104. Thigpen CA, Padua DA, Morgan N, et al. Scapular kinematics during supraspinatus rehabilitation exercise: a comparison of full-can versus empty-can techniques. Am J Sports Med 2006;34:644-52.

105. Fleck SJ, Kraemer WJ. Designing resistance training programs. Champaign, Illinois, USA: Human Kinetics Publishers, 1987.

106. Moncrief SA, Lau JD, Gale JR, et al. Effect of rotator cuff exercise on humeral rotation torque in healthy individuals. J Strength Cond Res 2002;16:262-70.

107. Niederbracht $\mathbf{Y}$, Shim AL, Sloniger MA, et al. Effects of a shoulder injury prevention strength training program on eccentric external rotator muscle strength and glenohumeral joint imbalance in female overhead activity athletes. $J$ Strength Cond Res 2008;22:140-5.

108. Rathburn JB, MacNab I. The microvascular pattern of the rotator cuff. J Bone Joint Surgery (Br) 1970;52-B:540-53.

109. Graichen H, Hinterwimmer S, von Eisenhart-Roth RVR, et al. Effect of abducting and adducting muscle activity on glenohumeral translation, scapular kinematics and subacromial space width in vivo. J Biomech 2005;38:755-60.

110. Bitter NL, Clisby EF, Jones MA, et al. Relative contributions of infraspinatus and deltoid during external rotation in healthy shoulders. J Shoulder Elbow Surg 2007; 16:563-8.

111. Bassett RW, Browne A0, Morrey BF, et al. Glenohumeral muscle force and moment mechanics in a position of shoulder instability. J Biomech 1990;23:405-15.

112. Fleisig GS, Andrews JR, Dillman CJ, et al. Kinetics of baseball pitching with implications about injury mechanisms. Am J Sports Med 1995;23:233-9.

113. Ellenbecker TS, Davies GJ, Rowinski MJ. Concentric versus eccentric isokinetic strengthening of the rotator cuff. Objective data versus functional test. Am J Sports Med 1988;16:64-9.

114. Mont MA, Cohen DB, Campbell KR, et al. Isokinetic concentric versus eccentric training of shoulder rotators with functional evaluation of performance enhancement in elite tennis players. Am J Sports Med 1994;22:513-17.

115. Kuhn J. Exercise in the treatment of rotator cuff impingement: a systematic review and a synthesized evidence-based rehabilitation protocol. J Shoulder Elbow Surg 2009;18:138-60. 